\title{
Studies on crystals of D-, L-, and DL-alaninato nickel(II) complexes
}

\author{
Awni Khatib · Fathi Aqra
}

Received: 31 May 2009/Accepted: 16 July 2009/Published online: 2 August 2009

(c) The Author(s) 2009. This article is published with open access at Springerlink.com

\begin{abstract}
An attempt to link the heat of reaction obtained from analysis of UV spectra, bond energies deduced from crystallographic data and calorimetric measurements of [bis(D-, L-, and DL-alaninato)diaqua] nickel(II) dihydrate complexes to theoretical values obtained from calculation is described. The heat of reaction, which includes energy of ligand exchange in addition to crystal field stabilization energy of the three complexes, was calculated from changes in spectral shifts, bond lengths, and free energy between nickel(II) ion and the D-, L-, and DL-alanine complexed nickel(II) ion in aqueous solution. These investigations were done by UV-visible spectroscopy, $\mathrm{X}$-ray crystallography, and isothermal calorimetry. The results reveal that the experimental heat of reaction based on the three mentioned parameters is in good agreement with the theoretical value. The results are found to be of considerable interest in its linking of spectrochemical quantities with thermodynamic functions.
\end{abstract}

\section{Introduction}

Metals bound to amino acids are essential for the catalytic function of certain enzymes [1-7]. The synthesis, spectrochemical properties, structure, stability, thermochemical study, and characterization of complexes of copper(II), nickel(II), cobalt(II), and zinc(II) with histidine, glycine, alanine, and other amino acids have previously been reported [8-14]. Standard molar enthalpies of formation of glycine and alanine in the gaseous phase on the basis of

A. Khatib $(\bowtie) \cdot$ F. Aqra

Department of Chemistry, Faculty of Science and Technology, Hebron University, P O Box 40, Hebron, West bank, Palestine

e-mail: awni51@hotmail.com theoretical calculations have recently been studied [15]. In thermodynamics and physical chemistry, thermochemistry is the study of the energy evolved or absorbed in chemical reactions and any physical transformations, such as melting and boiling. Thermochemistry, generally, is concerned with the energy exchange accompanying transformations such as mixing, phase transitions, chemical reactions, and including calculations of such quantities as the heat capacity, heat of combustion, heat of formation, enthalpy, and free energy. Therefore, thermochemistry is a quantitative subject and demands that reactions are carefully defined and that physical states of the substances discussed are fully and clearly documented. For this reason, it is important to understand thermodynamic relationships involved in the actual reaction between metal cations and a variety of ligands. Simple chemical reactions involve changes in parameters such as bond length, bond angles, electronic spectral shifts and free energy as reactants become products. This paper describes a relatively simple system of reactants and products that makes it possible to determine how well experimental results can be described by theory. The system consists of nickel(II) ion that forms 1:2 complexes with D-, L-, and DL-alanine. This system has several advantages: firstly, nickel(II) ion has an absorption spectrum in the UV-visible range, and undergoes spectral shifts when it forms complexes with alanine. Secondly, the complexes readily crystallize and can be studied by X-ray crystallography and isothermal calorimetry in order to observe changes in free energy. The chemical changes that occur in reactants and products are reflected by color changes as a result of shifts in spectral peaks and by changes in the bond lengths within reactants compared to products and, therefore, can be described thermodynamically as changes in free energy. The illustrated system of reactants and products (nickel(II) complexes with alanine) 
makes it possible to determine how well experimental results correlate with theory.

\section{Experimental}

Complexes of [Bis(D-, L- and DL-alaninato)diaqua] nickel(II) dihydrate [16] were prepared by mixing nickel sulfate solutions in de-ionized water $(0.10 \mathrm{M})$ with $\mathrm{D}^{-}, \mathrm{L}-$ and $\mathrm{DL}^{-}$ alanine solutions $(0.20 \mathrm{M})$ in $1: 2$ ratio, $\mathrm{pH} 8.5$ [17]. The complexes formed were monitored by UV-vis spectrometry [18]. The resulting solution was supersaturated, left for several days yielding crystals, which were isolated for Xray diffraction studies. The complex formation was $\mathrm{pH}-$ dependent and only occurred at basic $\mathrm{pH}$ ranges where the carboxyl group of the alanine was present in its anionic form. It was shown that the ligand exchange is $\mathrm{pH}$ influenced and it appears that the alanine reacts as a monodentate ligand through its carboxylic group, and at higher $\mathrm{pH}$ it binds from its amine end [19]. Spectral shifts were monitored as nickel(II) ion reacted with alanine to form complexes. Spectra were measured and recorded with either a Gilford or a Hewlett-Packard UV-Vis spectrophotometer. For hexaaqua nickel(II) at $\mathrm{pH}=6$, the absorption maxima were at 302, 382 and $644 \mathrm{~nm}$. For Bisalaninato-diaqua nickel(II) at $\mathrm{pH}=8.5$, the absorption maxima were at $302,370.5$ and $618.5 \mathrm{~nm}$.

\section{Crystallization conditions and X-ray diffraction}

Crystallization was induced either by concentrating the solution under nitrogen or by letting it stand for several days on the bench. After several days of incubation, two kinds of crystals formed in this solution: pale blue-prismlike and blue-rhombic. Small, well-formed crystals were chosen by microscopic examination for crystallographic studies. The crystal structures and crystallographic data of the nickel(II) complexes with D, L, and DL-alanine previously reported with CCDC 718340, 718341, 716012, VAGWAB, and BUNVOV01 [20-25] have been investigated in order to establish whether possible differences related to chiral influences could be detected.

\section{Isothermal calorimetry}

Heats of reaction of nickel(II) complexes with D-, L-, and DL-alanine were determined in order to establish whether chirality had any effect on enthalpy of the reaction. Enthalpy changes were measured at $30^{\circ} \mathrm{C}$ with an ITC (VP-ITC Micro-Calorimeter by MicroCal, LLC, Northampton, MA-USA). The reactants were nickel(II) ion as chloride or sulfate salts and alanine at $\mathrm{pH}=8.0$, and the concentration was constant at $100 \mathrm{mM}$. The products were
bis-D-, L-, and DL-alaninato diaqua nickel(II), and the concentrations of the alanine ( $\mathrm{L}, \mathrm{D}$ and $\mathrm{DL}$ ) were varied from 100, 50, 5, and $0.25 \mathrm{mM}$, The nickel(II) ion (3 microliter aliquots) was injected into $2 \mathrm{~mL}$ of the alanine solution in the instrument cell. Injections were repeated 10 times at 3 min intervals, and the heat of reaction was recorded when the same value was measured in five or more injections.

\section{Results and discussion}

Free energies were calculated from spectral shifts using $E \lambda_{\max }=h(c / \lambda)=h c \dot{b}$ (where $b$ is the wavenumber, $h$ is Plank's constant, and $c$ is the electromagnetic radiation velocity). If an absorption peak was shifted, the free energy difference $\Delta E$ between reactants and products was calculated as follows: $h c \Delta b=\Delta E=E$ at $\lambda_{\max a}-E$ at $\lambda_{\max b}$. The general relationship between bond energies and bond length is inversely proportional when dealing with atoms of comparable size, but there is no clear correlation when there are large differences in the covalent radii of atoms.

Heats of reaction were first calculated from UV-visible band shifts upon complex formation when nickel(II) ion reacted with alanine. Energy differences were also calculated using bond energies extrapolated from bond length differences established by X-ray crystallography [23-25]. The calculated values were then compared with experimental values determined by isothermal calorimetry.

$\Delta \mathrm{H}$ reaction in $\mathrm{kJ} / \mathrm{mol}$ for $\mathrm{Ni}(\mathrm{II})$ alanine complexes: calorimetry $=15.1 \pm 0.7, \mathrm{X}$-ray crystallography $=16.0 \pm$ 0.20 , spectral shifts $=17.1 \pm 0.14$. These experiments were performed thrice in order to make the results reproducible, and therefore, the heats of reaction are quoted with associated errors, which were obtained from differences of the three trials. The reported differences are statistically meaningful, and the results of this experiment are described.

For the green aquated nickel(II) ion at $\mathrm{pH}=6.0$, there are three characteristic bands at 302, 382, and $644 \mathrm{~nm}$. For the blue bis-alaninato diaqua nickel(II) complex at $\mathrm{pH}=8.5$, the bands are at 302, 370.5, and 618.5. The calculated energy associated with this blue shift was $-9,720 \mathrm{~J} / \mathrm{mol}$ for the second band and $-7,350 \mathrm{~J} / \mathrm{mole}$ for the third band shift. Adding both shifts gives $-17,070 \mathrm{~J} / \mathrm{mol}$.

The complexes of nickel with $\mathrm{D}, \mathrm{L}$, and DL-alanine exhibited slight differences in bond lengths [23-25], particularly the Ni-N1 bond, but these were not significant within the standard uncertainty associated with X-ray diffraction analysis. The crystallographic results for the nickel(II) alanine complexes established an average bond length of $208.6 \mathrm{pm}$ for $\mathrm{Ni}-\mathrm{O}$ when the oxygen is water oxygen. The bond length decreases to $205.06 \mathrm{pm}$ when the $\mathrm{Ni}-\mathrm{O}$ is carboxylic oxygen, and to $207.06 \mathrm{pm}$ for the $\mathrm{Ni}-\mathrm{N}$ 
Table 1 Bond lengths in D- and L-alanine complexes with nickel ions

\begin{tabular}{llll}
\hline D-Alanine & Bond length in pm & L-Alanine & Bond length in pm \\
\hline Ni-O1 & $205.79(18)$ & Ni-O1 & $205.67(17)$ \\
Ni-O3 & $204.33(18)$ & Ni-O3 & $204.22(17)$ \\
Ni-N1 & $206.69(19)$ & Ni-N1 & $207.03(17)$ \\
Ni-N2 & $207.44(18)$ & Ni-N2 & $207.58(16)$ \\
Ni-O5 & $210.11(17)$ & Ni-O5 & $210.06(16)$ \\
Ni-O6 & $207.12(19)$ & Ni-O6 & $207.06(18)$
\end{tabular}

Replacing four water molecules by two alanine is equivalent to replacing $4 \mathrm{Ni}-\mathrm{OH}_{2}$ with $2 \mathrm{Ni}-\mathrm{Oi}-\mathrm{C}$ and $2 \mathrm{Ni}-\mathrm{Ni}-\mathrm{C}$. The bond lengths and differences are statistically significant when tested in terms of the standard uncertainty given in parentheses in the table

bond to the amine end of the alanine (Table 1). A review of all bond lengths, especially those in the range of $200 \mathrm{pm}$ revealed that a linear correlation can be drawn between bond length and bond energy and found to be $1.6 \mathrm{~kJ} /$ $\mathrm{pm}$ mol. Calculating the difference in bond lengths for the complex in which $4 \mathrm{Ni}-\mathrm{O}(\mathrm{H} 2)$ were replaced by $2 \mathrm{Ni}-\mathrm{OC}$ and $2 \mathrm{Ni}-\mathrm{NC}$ gives a total of $10.16 \mathrm{pm}$, which is equivalent to $-16.0 \mathrm{~kJ} / \mathrm{mol}$ (Table 2). The measured value of the heat of formation using ITC averages $-15.1 \mathrm{~kJ} / \mathrm{mol}$. This result is in reasonable agreement with the calculated energy. The DL-alaninato complex crystallizes as pale blue tabletshaped crystals from a water solution. This crystal structure was markedly different from the structures of the $\mathrm{D}$ and $\mathrm{L}$ alanine complexes [25].

In control experiments, the hydration energy for nickel(II) ion diluted into water from $0.10-0.5 \mathrm{M}$ solutions was found to be negligible $(-0.22 \mathrm{kcal} / \mathrm{mole})$. The exothermic heat of reaction between nickel(II) ions and optically active alanine was then measured during the formation of nickelalanine complexes to determine whether there were detectable differences. Examples of experimental results from the ITC are shown in Fig. 1. At a molar ratio of 1:1 (nickel

Table 2 Calculated heat of reaction from changes in bond lengths between reactants and products

Average bond length $\mathrm{Ni}(\mathrm{O} 1+\mathrm{O} 3)=\{205.79+204.33\} / 2=205.06$ Average bond length $\mathrm{Ni}(\mathrm{N} 1+\mathrm{N} 2)=\{206.69+207.44\} / 2=207.06$ Average bond length $\mathrm{Ni}(\mathrm{O} 5+\mathrm{O} 6)=\{210.11+207.12\} / 2=208.60$ Difference in bond length $=2\left\{\mathrm{NiO}_{\mathrm{H} 2}-\mathrm{NiO}_{\mathrm{C}}\right\}+2\left\{\mathrm{NiO}_{\mathrm{H} 2}-\mathrm{NiN}_{\mathrm{C}}\right\}$ The difference in bond length $=2\{208.60-205.06\}+2\{208.60-$ $207.12\}=10.16 \mathrm{pm}$

The difference in calculated energy $=10.16 \mathrm{pm} \times 1.6 \mathrm{~kJ} / \mathrm{mol} \mathrm{pm}=$ $16 \mathrm{~kJ} / \mathrm{mol}$

Standard uncertainties of the bond lengths determined by X-ray diffraction are negligible and were therefore not included in the calculations of heat of formation

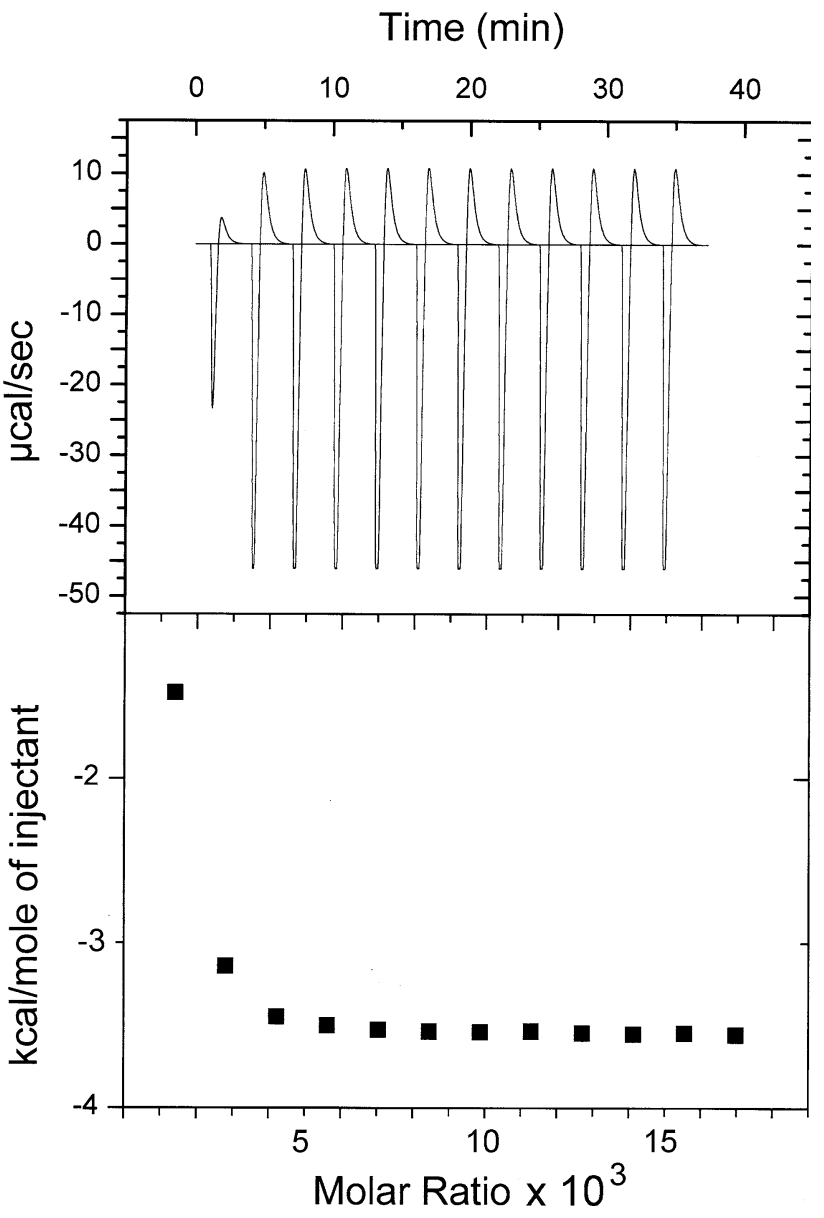

Fig. 1 Isothermal calorimetry of nickel ions reacting with D-alanine

injection into $0.25 \mathrm{mM}$ alanine), the heat of reaction was $-8.4 \mathrm{~kJ} / \mathrm{mole}$. This indicates the binding between $\mathrm{Ni}(\mathrm{II})$ atom and alanine as unidentate, the binding mainly takes place at the carboxylic end. A lower value indicates that the reaction had not gone to completion in the dilute solution of nickel and alanine. When the molar ratio of nickel ion to alanine was $1: 2$, the heat of formation was $-15.1 \mathrm{~kJ} / \mathrm{mol}$. The higher value indicates a virtually complete reaction of the more concentrated nickel(II) ion with alanine.

The terms required to calculate heats of reaction include $\Delta H_{\text {atm }}, \Delta H_{\text {ionization }}, \Delta H_{\text {dissociation }}, \Delta H_{\text {electron affinity, and }}$ $\Delta \mathrm{H}_{\text {lattice. }}$ These serve well in describing simple reactions between metals and nonmetals, but calculating the heat of reaction for complex ions or compounds in aqueous solutions becomes more problematic. The significance of the method presented here is that the heat of reaction can be calculated for complex reactions that are not reported in the literature as long as the free energy of the reaction is dominated by the enthalpy term.

In the reaction, the reactant is nickel(II) ion coordinated to six water molecules. When a complex forms between a 
metal ion and alanine, four of the water molecules are replaced by carboxyl and amino groups of the amino acid. The reaction produces measurable shifts in the UV-visible absorption bands when spectra of the reactant ions are compared with spectra of the products. Ligand field theory predicts that stronger ligands will cause a larger d-d transition, which will result in the absorption of a shorter wavelength. This shift reflects the relative strength of the bonds in the product compared to the same bonds in the reactant, and the free energy of the reaction is related to the degree of spectral shift. When the heat of reaction was calculated from spectral shifts during the reaction between nickel and alanine, it is found that the calculated value was a reasonable approximation of the energy measured by isothermal calorimetry. Because bond length is proportional to bond strength, it should also be possible to calculate free energy of a reaction simply by comparing changes in bond length between reactants and products. The free energy of the reaction between nickel and alanine, calculated from bond length changes determined by X-ray crystallography [23-25], also predicted the measured heat of reaction within experimental error. Correlation of free energy change to spectral shift would seem to imply that exited states were the same in reactants and products. The bond length-bond energy relationship is well known and its application in this system is potentially interesting even though we have only preliminary data at present.

\section{Conclusion}

The results of the illustrated method indicate that it is possible to estimate the heat of reaction of transition metal complexes from the analysis of UV spectra, X-ray crystallography, and isothermal calorimetry. Therefore, more derivatives such as the copper, iron, zinc, and cobalt alanines as well as perhaps the glycine complexes will be studied in future in order to develop a method for a general application and approach. Nickel(II) was chosen because it has intrinsic absorption peaks in the UV-visible range and readily forms complexes with alanine that have clear spectral band shifts as water of hydration is replaced by the amino acid ligands.
Acknowledgments We thank Mohammad Zhour, the university web master for computer assistance. Also, Awni Khatib wishes to thank the CIES and Fulbright for a Sabbatical at the University of California.

Open Access This article is distributed under the terms of the Creative Commons Attribution Noncommercial License which permits any noncommercial use, distribution, and reproduction in any medium, provided the original author(s) and source are credited.

\section{References}

1. Pickart L, Goodwin WH, Burgua W, Murphy TB, Johnson DK (1983) Biochem Pharmacol 32:3868

2. Zanello P, Tamburini S, Vigato PA, Mazzocchine GA (1987) Coord Chem Rev 77:165

3. Whitener GD, Hagardorn JR, Arnold J (1999) J Chem Soc Dalton Trans 1249

4. Que L, True AE (1990) Prog Inorg Chem 38:97

5. Colacio E, Mustapa G, Raikko K, Moreno JM (2000) Inorg Chem 38:2882

6. Rhule JT, Hill CL, Judd DA, Schinazi RF (1998) Chem Rev 98:327

7. Inoue M, Yamase T (1995) Bull Chem Soc Jpn 68:3055

8. Saxena VK, Gupta M, Srivastava MN (1996) Synth React Inorg Met Org Chem 26:1661

9. Bhagwat V, Sharma V (1976) Curr Sci 45:135

10. Sharma VS, Mathur HB, Biswas AB (1964) Indian J Chem 2:5

11. Mishra A, Mahajan M, Johar KK (2003) Indian J Pure Appl Phys 41:232

12. Di YY, Chen JT, Tan ZC (2008) Thermochimica Acta 471:70

13. Remelli M, Munerato C, Pulidori F (1994) J Chem Soc Dalton Trans 2049

14. Qu L, Liu Y, Tu L, Yan C, Qu S (2002) Peop Rep Chin 65:786

15. Dorofeeva OV, Ryzhova ON (2009) J Chem Thermodyn 41:433

16. Nakamoto K (1961) J Am Chem Soc 83:4528

17. Khatib A (1981) M.S. Thesis, Utah State University, Logan

18. Smith GG, Khatib AA, Ready GS (1983) J Am Chem Soc 105:293

19. Khatib AA, Engel MH (1989) Inorg Chim Acta 166:273

20. Mostad A, Natarajan S (1987) Z Kristallogr 178:263

21. Teoh SG, Chan BT, Fun HK, Kamwaya ME (1987) Z Kristallogr 181:199

22. Jianmin L, Cunwang G, Yugeng Z (1990) Cryst Res Technol 25:K5

23. Khatib A, Aqra F, Deamer D, Oliver A (2009) Res Lett Inorg Chem 1

24. Khatib A, Aqra F, Deamer D, Oliver A (2008) South Braz J Chem 16:23

25. Khatib A, Aqra F, Deamer D, Oliver A (2009) J Argent Chem Soc 97:1 